\title{
Assessment of left ventricular systolic and diastolic functions in severely malnourished children
}

\author{
Gihan M. Bebars ${ }^{*}$ and Hany T. Askalany
}

\begin{abstract}
Background: Malnourished children endure many changes in body composition and lose heart and skeletal muscle mass. Diastolic dysfunction is one of the major causes of heart failure with preserved ejection fraction.

Aim: To assess left ventricular systolic and diastolic functions in children with severe acute malnutrition using tissue Doppler imaging technique and to evaluate the effect of nutritional rehabilitation.

Patients and Methods: A follow-up case-control study conducted on 60 severely malnourished children (WHZ $<-$ 3SD) and 120 age and sex-matched healthy children as a control group. Tissue Doppler imaging (TDI) was done for all included malnourished children at admission and for control to measure left ventricular systolic and diastolic functions. Nutritional rehabilitation was done according to WHO protocol and tissue doppler was repeated after rehabilitation when (WHZ >-2SD) to detect any changes in systolic or diastolic functions.

Results: Systolic function was normal in malnourished children and control. Grade I diastolic dysfunction was detected in $40 \%$ and grade II in 30\% of severely malnourished children in comparison to 100\% normal diastolic function in control group. No correlations between diastolic dysfunction and either anthropometric measurements, electrolyte disturbances or $\mathrm{Hb} \%$ in malnourished children before nutritional rehabilitation. Mortality from sepsis with associated ventricular dysfunction grade II documented in 3.3\% of malnourished children. After nutritional rehabilitation diastolic function improved significantly as $65.6 \%$ of children attained normal diastolic function, $31 \%$ grade 1 and $3.4 \%$ grade II. Positive correlations between diastolic function and WAZ, HAZ, WHZ and MUAC after rehabilitation.

Conclusion: Severe acute malnutrition affects diastolic function in children which is reversible in most of these cases with rehabilitation. TDI is an easy and practical method for detection and follow-up of ventricular function in malnourished children.
\end{abstract}

Keywords: Severe malnutrition, Diastolic dysfunction, Systolic dysfunction, Tissue Doppler image

\section{Introduction}

Malnutrition is a major health issue accounting for approximately 3.1 million yearly deaths among children in low and middle-income countries, and it refers to both protein-energy malnutrition (PEM) and micronutrient deficiency [1].

Patients with severe PEM have multiple nutritional deficiencies, anaemia and frequent intercurrent illnesses. Moreover, PEM involves tissue protein all over the body

* Correspondence: gehan.mohamed@minia.edu.eg

Faculty of Medicine, Minia University, Children and Maternity Minia University Hospital, Minia, Egypt

(c) The Author(s). 2019 Open Access This article is distributed under the terms of the Creative Commons Attribution 4.0 International License (http://creativecommons.org/licenses/by/4.0/), which permits unrestricted use, distribution, and reproduction in any medium, provided you give appropriate credit to the original author(s) and the source, provide a link to the Creative Commons license, and indicate if changes were made. causing severe wasting of skeletal muscles including but less severely the heart muscles $[2,3]$. These may variably influence the cardiac function [4] and may result in an inherent ventricular dysfunction [3]. Myocardial disorders, whether cardiac arrhythmia or heart failure, are responsible for some deaths among kwashiorkor patients [5].

Tissue Doppler imaging (TDI) is a robust and reproducible ultrasound technique employing the low frequency and high-amplitude ultrasound signals reflected from the myocardium. Echocardiographic tissue Doppler imaging measures myocardial velocities and time to peak myocardial velocities with high temporal resolution permitting the

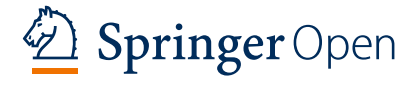


evaluation of left (LV) and right (RV) ventricular mechanics. Moreover, TDI is useful for screening and detection of subclinical myocardial dysfunction, and for evaluating the efficacy of therapeutic interventions [6, 7].

This study was designed to detect the myocardial affection in children with severe acute malnutrition (SAM) before and after nutritional rehabilitation using echocardiography and tissue Doppler imaging technique.

\section{Patients and methods}

A follow-up case-control study conducted over the period from August 2016 to January 2017 at Children and Maternity Minia University Hospital which is the main referral hospital for the governorate. The study was approved from the local ethical committee of the Faculty of Medicine at Minia University and informed oral consents were taken from care givers after explanation of the study purpose.

Studied children were subjected to full history taking with detailed nutritional history, clinical examination including anthropometric indices (weight, length, MUAC) using WHO Z-score growth charts optimal for their age and sex to determine the percentile for each parameter then were divided into 2 groups according to their nutritional status:

Group 1: included 60 infants and children recruited from inpatient nutritional rehabilitation unit who were admitted with the diagnosis of (SAM) by $\mathrm{WHZ}<-3 \mathrm{SD}$, MUAC $<115 \mathrm{~mm}$ or presence of bilateral pitting edema.

Group 2: 120 infants and children with normal anthropometric indices (WHZ > 2SD), they were age and sex matched with the first group and considered as a control group.

Children with; any documented cardiothoracic event, congenital heart disease, a metabolic disease as tyrosinemia, galactosemia, UCD, glycogen storage disease, chronic medical disease as cerebral palsy or chronic liver disease, history of prematurity or intrauterine growth retardation, and those with muscle disease or diabetes were excluded from our study.

Admitted children with SAM were managed according to WHO protocol for management of these cases and passed through initial stabilization phase and a rehabilitation phase according to WHO guidelines updates [8]. During treatment course at hospital, malnourished children were checked daily for weight gain and complications were treated.

Based on the routine follow-up at nutrition rehabilitation unit, all malnourished children who survived hospitalization were followed up for 6 months post-discharge in the following rate; weekly for the first 2 weeks then biweekly till the end of the 3rd month. Routine follow-up included anthropometric measurements and vital signs, as well as assessment and management of any intercurrent illness. Our goal was to reach WHO, 2012 [9] criteria for discharge from treatment:Weight-for-height/length is $\geq-2$ Z-score and no edema for at least 2 weeks, or mid-upper-arm circumference is $\geq 125 \mathrm{~mm}$ and no edema for at least 2 weeks.

\section{Blood samples}

$2 \mathrm{ml}$ venous blood samples were collected from all participants under complete aseptic technique for $\mathrm{CBC}$ and electrolytes at admission and at discharge from rehabilitation programe.

\section{Echocardiographic and tissue Doppler evaluation}

All participants were examined by transthoracic echocardiography using the Hewlett Packard (HP) Sonos 4500 using phased array transducers with a frequency of $8 \mathrm{MHZ}$. This was conducted while the child was in the recumbent or lateral decubitus position. All participants were subjected to M-mode, 2-dimensional echocardiography and tissue Doppler assessment using the standard views as a parasternal long axis, short axis, apical four, five chamber and subcostal views to evaluate the following parameters; LVEDD, LVESD, EF, FS and LA size [10], as well as exclusion of any wall motion abnormalities. Transmitral flow pattern: Using PW Doppler across the mitral inflow tract, two waves were measured: the early $\mathrm{E}$ wave corresponding to early ventricular filling and A wave which reflect atrial contraction was typically measured by placing a $2 \mathrm{~mm}$ sample volume at the mitral leaflet tips in the four chamber apical view. Tissue Doppler imaging mitral annular velocity was obtained by placing a $5 \mathrm{~mm}$ sample volume over the lateral or septal mitral annulus and also systolic $\mathrm{S}^{\prime}(\mathrm{Sa})$, early diastolic $\mathrm{E}(\mathrm{Ea})$ and the late diastolic velocities $\mathrm{A}^{\prime}(\mathrm{Aa})$ were measured [11].

\section{Fractional shortening (FS) percent}

The following equation was adopted to calculate the LV FS:

$$
\mathrm{FS}=\frac{\text { LVEDD }- \text { LVESD }}{\text { LVEDD }} * 100 \%
$$

where, LVEDD refers to the end-diastolic diameter of the left ventricle and LVESD refers to the end-systolic diameter of the left ventricle.

\section{Ejection fraction (EF)}

The "cubed equation" was adopted to calculate the Ejection fraction:

$$
\mathrm{EF}(\%)=(\mathrm{EDV}-\mathrm{ESV}) * 100 / \mathrm{EDV}
$$

\section{LV diastolic function (E/A)}

Using E/A ratio of the mitral flow by pulsed wave Doppler across the mitral valve and e by tissue Doppler [11]. Normal diastolic function was identified when LA volume 
index $<34 \mathrm{ml} / \mathrm{m} 2$, with medial mitral annular $\mathrm{e}^{\prime} \geq 8 \mathrm{~m} / \mathrm{s}$, and lateral mitral annular $\mathrm{e}^{\prime} \geq 10 \mathrm{~ms} / \mathrm{s}$. Diastolic dysfunction (DD) was diagnosed if the following 3 criteria were met: LA volume index $\geq 34 \mathrm{ml} / \mathrm{m} 2$; medial annular $\mathrm{e}^{\prime}<8 \mathrm{~m} / \mathrm{s}$; and lateral annular $\mathrm{e}^{\prime}<10 \mathrm{~m} / \mathrm{s}$. Further categorization of DD into severity grades 1,2 , or 3 was performed using the mitral E/A ratio, E-wave deceleration time, average E/e' value, and peak pulmonary systolic pressure [11].

\section{Methods of statistical analysis}

SPSS (statistical program for social science, version 13.0) was used for analysis of the gathered data. Continuous variables were presented as a mean \pm standard deviation (SD), and categorical variables were presented as a frequency and percentage. $P$-value $<0.05$ considered significant. One-way ANOVA was used to analyze quantitative data while chi-square was used to analyze qualitative data. The Chi-square $\left(\mathrm{X}^{2}\right)$ was used to compare more than one proportion.

\section{Results}

No significant difference between both groups regarding maternal working status as $90 \%$ \& $83.3 \%$ of mothers in SAM group healthy children group respectively were housewives. Rural residence was of significant relation to malnutrition as $86.6 \%$ of them were belonging to rural residence, also $93.4 \%$ were of very low and low socioeconomic standards in comparison to $41.7 \%$ were of low socioeconomic standards in the healthy group and the rest of them were from middle and high socioeconomic standards (30\% \& 28.3\%). No significant differences between both groups regarding their age or sex but the malnourished group had a birth weight that was significantly lower than the control group $(P<0.001)$ and were dependent mainly on breastfeeding $66.7 \%(P<0.03)$ with deficient complementary feeding. The most frequent comorbidities associated with malnutrition were dehydration $31.9 \%$ followed by bronchopneumonia $23 \%$, sepsis $20.7 \%$ and gastroenteritis $11.1 \%$.

Malnourished children have a significantly lower anthropometric indices, hemoglobin, potassium and calcium levels in comparison to control group $(P<0.001)$.

In SAM children diastolic dysfunction grade II was detected in thirty percent (30\%), while $40 \%$ have diastolic dysfunction grade I and 30\% preserved normal diastolic function in comparison to $100 \%$ normal diastolic function in healthy group $(P<0.001)$. Both SAM and healthy children have a normal systolic function (Table 1).

Two cases died during treatment course at hospital, they were suffering from sepsis and diastolic dysfunction grade II was detected in both cases by tissue doppler imaging (date to death was about14 days from admission).
Table 1 Comparison between baseline tissue Doppler findings in studied children (PEM and control group) at admission

\begin{tabular}{|c|c|c|c|}
\hline Data & Malnourished children $(N=60)$ & Controls $(N=120)$ & $P$-value \\
\hline E & $0.7 \pm 0.2$ & $0.9 \pm 0.1$ & $0.001^{* *}$ \\
\hline A & $0.7 \pm 0.1$ & $0.6 \pm 0.1$ & 0.07 \\
\hline E/A & $1.08 \pm 0.3$ & $1.4 \pm 0.1$ & $0.001^{* *}$ \\
\hline É & $0.15 \pm 0.1$ & $0.13 \pm 0.01$ & 0.3 \\
\hline E/é & $8.6 \pm 3.2$ & $7.3 \pm 1.4$ & $0.01^{*}$ \\
\hline EF & $68.03 \pm 3.7$ & $71.4 \pm 5.6$ & $0.001^{* *}$ \\
\hline FS & $38.8 \pm 5.01$ & $39.6 \pm 3.3$ & 0.3 \\
\hline \multicolumn{4}{|c|}{ Diastolic function } \\
\hline Normal & $18(30 \%)$ & $120(100 \%)$ & $0.001^{* *}$ \\
\hline Grade I & $24(40 \%)$ & 0 & \\
\hline Grade II & 18(30\%) & 0 & \\
\hline \multicolumn{4}{|c|}{ Systolic function } \\
\hline Normal & $60(100 \%)$ & 120(100\%) & 0.5 \\
\hline
\end{tabular}

A statistically significant improvement in all anthropometric indices (WAZ, WHZ, HAZ, MUAC) were documented in survived malnourished children $(P<0.001)$ after nutritional rehabilitation (Table 2) with a significant improvement in their hemoglobin level without blood transfusion also serum $\mathrm{K}$ and $\mathrm{Ca}$ reached their normal levels $(P<0.001)$ in comparison to at admission parameters. The previously affected left ventricular diastolic function improved significantly to be $65.6 \%$ normal, $31 \%$ grade I and $3.4 \%$ grade II diastolic dysfunction $(P<0.005)$ after nutritional rehabilitation (Table 3). No significant correlations were detected between diastolic dysfunction in PEM and their baseline anthropometric measurements at admission but positive correlations were detected between WAZ, HAZ, WHZ and MUAC and diastolic function after nutritional rehabilitation (Tables 4 and 5).

Still no significant changes observed with nutritional rehabilitation on left ventricular systolic function.

\section{Discussion}

Severe acute malnutrition (SAM) is a huge global public health issue which is up till now a significant cause of childhood mortality all over the world [12, 13].

This study revealed that the majority of malnourished children were related to rural residents with low or very low social standards and these results may be due to the fact that undernutrition is strongly related to the low income and social standard and also, it is related with the rural conditions. Different authors documented that severe acute malnutrition is associated with the poor standard of living and living in rural regions [14-16]. The association of a higher percentage of breastfeeding 
Table 2 Comparison between at admission and after nutritional rehabilitation anthropometric measurements in children with severe acute malnourished (SAM)

\begin{tabular}{|c|c|c|c|c|c|}
\hline & \multicolumn{2}{|c|}{$\begin{array}{l}\text { Before nutrional } \\
\text { rehabilitation }\end{array}$} & \multicolumn{2}{|c|}{$\begin{array}{l}\text { After nutrional } \\
\text { rehabilitation }\end{array}$} & \multirow[t]{3}{*}{$P$-value } \\
\hline & Frequency & Percentage $\%$ & \multirow{2}{*}{$\begin{array}{l}\text { Frequency } \\
\text { (58) }\end{array}$} & \multirow[t]{2}{*}{ Percentage\% } & \\
\hline & -60 & & & & \\
\hline \multicolumn{6}{|l|}{ WAZ score } \\
\hline$<0,>-1 \mathrm{SD}$ & 0 & 0 & 28 & 48.3 & \multirow[t]{3}{*}{$<0.001^{* * * *}$} \\
\hline$<-1,>-2$ SD & 0 & 0 & 30 & 51.7 & \\
\hline$<-3 \mathrm{SD}$ & 60 & 100 & 0 & 0 & \\
\hline \multicolumn{6}{|l|}{ HAZ score } \\
\hline$<0,>-1 S D$ & 0 & 0 & 28 & 48.3 & \\
\hline$<-1,>-2 S D$ & 16 & 26.7 & 30 & 51.7 & \multirow[t]{3}{*}{$<0.001^{* * *}$} \\
\hline$<-2,>-3 \mathrm{SD}$ & 28 & 46.7 & 0 & 0 & \\
\hline$<-3 S D$ & 16 & 26.7 & 0 & 0 & \\
\hline \multicolumn{6}{|l|}{ WHZ score } \\
\hline$<0,>-1 S D$ & 0 & 0 & 32 & 55.2 & \\
\hline$<-1,>-2 S D$ & 0 & 0 & 26 & 44.8 & \multirow[t]{3}{*}{$<0.001^{* * * *}$} \\
\hline$<-2,>-3 \mathrm{SD}$ & 2 & 3.3 & 0 & 0 & \\
\hline$<-3 S D$ & 58 & 96.7 & 0 & 0 & \\
\hline \multicolumn{6}{|l|}{ MAUC Z score } \\
\hline$<0,>-1 \mathrm{SD}$ & 0 & 0 & 32 & 55.2 & \multirow[t]{3}{*}{$<0.001^{* * * *}$} \\
\hline$<-1,>-2 S D$ & 0 & 0 & 26 & 44.8 & \\
\hline$<-3 S D$ & 60 & 100 & 0 & 0 & \\
\hline \multicolumn{6}{|c|}{ Head circumference for age $Z$ score } \\
\hline \multicolumn{6}{|l|}{$<0,>-1 \mathrm{SD}$} \\
\hline$<-1,>-2$ SD & 42 & 70 & 50 & 86.2 & \\
\hline \multirow[t]{2}{*}{$>0 S D$} & 18 & 30 & 0 & 0 & \\
\hline & 0 & 0 & 8 & 13.8 & $0.001^{* *}$ \\
\hline
\end{tabular}

Mc-Nemar test

Table 3 Comparison between Tissue Doppler findings in children with SAM before and after nutritional rehabilitation

\begin{tabular}{llll}
\hline Data & $\begin{array}{l}\text { (before nutritional } \\
\text { rehabilitation) } \\
(N=60)\end{array}$ & $\begin{array}{l}\text { (after nutritional } \\
\text { rehabilitation) } \\
(N=58)\end{array}$ & 0.1 \\
\hline E & $0.7 \pm 0.2$ & $0.9 \pm 0.6$ & $0.7 \pm 0.1$ \\
A & $0.7 \pm 0.1$ & $1.1 \pm 0.3$ & 0.4 \\
E/A & $1.08 \pm 0.3$ & $0.15 \pm 0.1$ & 0.6 \\
é & $0.15 \pm 0.1$ & $8.1 \pm 2.8$ & 0.7 \\
E/é & $8.6 \pm 3.2$ & $67.1 \pm 12.8$ & 0.6 \\
EF & $68.03 \pm 3.7$ & $37.9 \pm 3.9$ & 0.7 \\
FS & $38.8 \pm 5.01$ & $38(65.6 \%)$ & 0.3 \\
Diastolic function & & $18(31 \%)$ & $0.005^{* *}$ \\
Normal & $18(30 \%)$ & $2(3.4 \%)$ & 0.5 \\
Grade I & $24(40 \%)$ & $58(100 \%)$ & \\
Grade II & $18(30 \%)$ & & \\
Systolic function & & & \\
Normal & $60(100 \%)$ & & \\
\hline
\end{tabular}


Table 4 Correlation between diastolic function by TDI and anthropometric measurements of the studied children with SAM before and after nutritional rehabilitation

\begin{tabular}{|c|c|c|c|c|}
\hline \multirow[t]{3}{*}{ Parameter } & \multicolumn{4}{|c|}{ Diastolic functions } \\
\hline & \multicolumn{2}{|c|}{$\begin{array}{l}\text { Before } \\
\text { rehabilitation }\end{array}$} & \multicolumn{2}{|c|}{$\begin{array}{l}\text { After } \\
\text { rehabilitation }\end{array}$} \\
\hline & $r$ & $P$-value & $r$ & $P$-value \\
\hline WAZ score & - & - & 0.556 & $0.002^{* *}$ \\
\hline HAZ score & -0.236 & 0.210 & 0.417 & $0.024^{*}$ \\
\hline MUAC z score & - & - & 0.379 & $0.042^{*}$ \\
\hline WHZ z score & - & - & 0.379 & $0.042^{*}$ \\
\hline Head circumference for age z score & -0.240 & 0.202 & 0.288 & 0.130 \\
\hline Edema & 0.173 & 0.362 & & \\
\hline
\end{tabular}

Spearman bivariate correlation

N.B. correlation cannot be computed for WAZ score, MUAC zscore, WHZ score because all cases have the same score (constant score)

with malnutrition in our study (66.7\%) suggests that breastfeeding in these cases was insufficient for their normal growth which may be due to prolonged breastfeeding, breastfeeding without optimal supplementation or if the mother is weak, underweight and malnourished related to their poor socioeconomic standards and this was in agreement with Berkley et al., 2005 [17].

The most common comorbidities detected with malnourished were dehydration, followed by bronchopneumonia and gastroenteritis. These ratios were close to those reported by Kerac et al., (2010), WHO (2013), Chisti et al., (2014) and Manisha et al., 2016 [2, 18-20].

Tissue Doppler imaging for children with SAM at admission in comparison to healthy controls; found no affection of the left ventricular systolic function parameters including ejection fraction (EF) and fractional shortening (FS) in both groups. Comes inline with our result was Olivares et al., who reported no affection in systolic function in children with PEM [21].

However, Singh et al., 1989, Phornphatkul et al., 1994 and Nagla et al., 2010 reported that children with severe cases of PEM with more than $40 \%$ loss of the expected weight have reduced LV systolic function [22-24].

The variability of the aforementioned results could be attributed to other factors, for instance, the severity of the electrolyte imbalance or trace element deficiency which affect LV systolic function.

A diastolic dysfunction in $70 \%$ of malnourished children was reported in our study. In more details; a significantly decreased $\mathrm{E}$ velocities, indicating diastolic myocardial abnormalities, and increased $\mathrm{E} / \mathrm{e}^{\prime}$ ratio at the lateral wall, which is a correlate of myocardial relaxation and LV filling pressure, in comparison to the healthy control children. Moreover, a negative but insignificant correlation between height for age $\mathrm{Z}$ score and $\mathrm{E} / \mathrm{e}^{\prime}$ was documented in children suffering from SAM.

Although our studied children with SAM have significantly lower hemoglobin, ionized calcium and serum potassium levels in comparison to the healthy control group but, the degree of diastolic dysfunction detected in those patients was not correlated with these deficiencies.

The previous findings reported in our study were on the contrary to El-Sayed et al., 2006 and Nagla et al.,

Table 5 Description of diastolic dysfunction grades in relation to anthropometric measurements in children with SAM after nutritional rehabilitation

\begin{tabular}{|c|c|c|c|c|}
\hline & & \multicolumn{3}{|c|}{ Diastolic function at discharge } \\
\hline & & $\begin{array}{l}\text { Normal diastolic } \\
\text { function } N=38\end{array}$ & $\begin{array}{l}\text { Diastolic } \\
\text { dysfunction } \\
\text { grade I } N=18\end{array}$ & $\begin{array}{l}\text { Diastolic } \\
\text { dysfunction } \\
\text { grade } \| N=2\end{array}$ \\
\hline \multirow[t]{2}{*}{ WAZ } & $<0,>-1$ & $26(68.4 \%)$ & $2(11.1 \%)$ & $0(\%)$ \\
\hline & $<-1,>-2$ & $12(31.6 \%)$ & 16(88.9\%) & $2(100 \%)$ \\
\hline \multirow[t]{2}{*}{$\mathrm{HAZ}$} & $<0,>-1$ & $24(63.2 \%)$ & $4(22.2 \%)$ & $0(0 \%)$ \\
\hline & $<-1,>-2$ & $14(36.8 \%)$ & 14(77.8\%) & $2(100 \%)$ \\
\hline \multirow[t]{2}{*}{ WHZ } & $<0,>-1$ & $26(68.4 \%)$ & $6(33.3 \%)$ & $0(0 \%)$ \\
\hline & $<-1,>-2$ & $12(31.6 \%)$ & $12(66.7 \%)$ & $2(100 \%)$ \\
\hline \multirow{2}{*}{$\begin{array}{l}\text { MAUC for } \\
\text { age }\end{array}$} & $<0,>-1$ & $26(68.4 \%)$ & $6(33.3 \%)$ & $0(0 \%)$ \\
\hline & $<-1,>-2$ & $12(31.6 \%)$ & $12(66.7 \%)$ & $2(100 \%)$ \\
\hline
\end{tabular}


2010 where no alteration in $\mathrm{E}$ or $\mathrm{E} / \mathrm{e}^{\prime}$ were detected in patients with PEM in comparison to control group using echocardiography $[25,24]$.

Nutritional rehabilitation was palned according to WHO standardized protocol for management of severe malnutrition and complications were managed accordingly [8].

Similar to the results obtained by Kerac et al., 2014, Public Health Foundation of India, 2012, Stettler and Iotova, 2010 and Dulloo, 2008 [26-29], a marked improvement was observed in all anthropometric indices of studied severely malnourished children after nutritional rehabilitation, regarding WHZ, WAZ and MUAC.

Marked improvement in hemoglobin level and normalization of TLC count, serum potassium, and serum calcium were detected in children with SAM at discharge from nutrition rehabilitation program and these data are in agreement with the results in other studies $[24,26]$.

During the treatment course at hospital, 2 cases died due to septic shock and this happened within two weeks after admission, their TDI revealed diastolic dysfunction grade II .

TDI for children with SAM post rehabilitation showed that $65 \%$ have a normal diastolic function in comparison to pre-rehabilitation with $70 \%$ diastolic dysfunction (P value $>0.001$ ). Different degrees of positive correlations between diastolic function and anthropometric measurements (WAZ, HAZ, WHZ, MUAC) after rehabilitation were detected. Recently, Spaulding et al., 2016 reported that children with severe malnutrition suffer cardiac muscle wasting and ventricular dysfunction that responds well to nutritional rehabilitation therapy, also Nagla et al., 2010 concluded that nutritional rehabilitation reverses cardiac abnormalities significantly [3, 24].

The current study is the first to evaluate ventricular dysfunction by TDI in children with SAM. This differences between this study and other studies could be attributed to the variable subject ages or the different disease severity and/or duration.

We concluded from our study that most children with SAM have ventricular diastolic dysfunction which improves to a great extent after nutritional rehabilitation. Impaired diastolic function in malnourished children may be a predictor of mortality in these cases. Also, we recommend the use of Tissue Doppler as a follow-up tool for prognostic evaluation and risk stratification in severely malnourished children as it has the advantage of simple, easy detection, lower expense, easily repeated measurement and convenient monitoring of outcome.

\section{Acknowledgements}

We would like to thank all families who accepted to participate in our study and gave us a lot of their time and effort, without them we caould not complete this work.

\section{Competing interests}

The authors declare that they have no competing interests.

Received: 12 July 2018 Accepted: 13 November 2018

Published online: 04 November 2019

\section{References}

1. Black RE, Victora CG, Walker SP et al (2013) Maternal and child under nutrition and overweight in low-income and middle-income countries. Lancet. 382:427-451

2. Manisha DK, Kumar SS (2017) A hospital based Study on Comorbidities in children with severe acute malnutrition. Pediatr Rev: Int J Pediatr Res. 4:01

3. Spaulding-Barclay MA, Stern J, Mehler PS (2016) Cardiac changes in anorexia nervosa. Cardiol Young. 26(4):623-628

4. Ratcliffe LE, Thomas W, Glen J et al (2016) Diagnosis and management of iron deficiency in CKD: a summary of the NICE guideline recommendations and their rationale. Am J Kidney Dis. 67(4):548-558

5. Olowonyo MT, Ogunkunle OO, Akinbami FO, Jaiyesimi F (1995) The echocardiographic findings in kwashiorkor. J Trop Pediatr. 41:74-76

6. Correale M, Totaro A, leva R, Brunetti ND, Di Biase M (2011) Time intervals and myocardial performance index by tissue Doppler imaging. Int Emer Med. 6(5):393-402

7. Geyer H, Caracciolo G, Abe H et al (2010) Assessment of myocardial mechanics using speckle tracking echocardiography: fundamentals and clinical applications. J Am Soc Echocardiogr. 23(4):351-369

8. WHO (2013) Guideline: updates on the management of severe acute malnutrition in infants and children. World Health Organization, Geneva ISBN-13: 978-92-4-150632-8

9. WHO (2012) Nutrition experts take action on malnutrition. World Health Organization http://www.who.int/kms/guidelines_review_committee/en/

10. Salem M, El Behery S, Adly A, Khalil D, El H (2009) Early E. Predictors of myocardial disease in children and adolescence with type 1 diabetes mellitus. Pediatr Diabetes. 10:513-521

11. (2015) Cardiovascular Imaging. Eur Heart J. 16(2):119-146. https://doi.org/10. 1093/ehjci/jeu210

12. Collins S (2007) Treating severe acute malnutrition seriously. Arch Dis Child. 92:453-461

13. WHO (2015) Global database on child growth and malnutrition. World Health Organization http://www.citeseerx.ist.psu.edu/viewdoc/ download?doi=10.1.1.392.5515\&rep.

14. Zzati M, Vander Hoorn S, Lawes CMM et al (2005) Rethinking "the diseases of affluence" paradigm: global patterns of nutritional risks in relation to economic development. PLoS Med. 2(5):e133. https://doi.org/10.1371/ journal.pmed.0020133 Academic

15. Yang W, Li X, Li Y et al (2012) Anemia, malnutrition and their correlations with sociodemographic charactristics and feeding practices among infants aged 0-18 months in rural areas of Shaanxi province in northwestern China: a cross-sectional study. BMC Public Health. 12:1127

16. Sebsibe T, Yinges A (2015) Urban-rural differentials in child under nutrition in Ethiopia. Int J Nutr Metab. 7(1):15-23

17. Berkley J, Mwangi I, Griffiths K et al (2005) Assessment of severe malnutrition among hospitalized children in rural kenya comparison of weight for height and mid upper arm circumference. JAMA. 294(5): 591-597 Reprinted

18. Kerac CMG, Collins S, Bahwere P, Seal A, Bunn J (2010) Long-term mortality and nutritional status following severe acute malnutrition: a longitudinal cohort study. Arch Dis Child. 95:A4

19. WHO. Updates On The Management Of Severe Acute Malnutrition In Infants And Children 2013. http://apps.who.int/iris/bitstream/10665/95584/1/ 9789241506328 _eng.pdf.

20. Chisti MJ, Graham SM, Duke T et al (2014) Post-discharge mortality in children with severe malnutrition and pneumonia in bangladesh. PLoS One. 9(9):e107663

21. Olivares JL, Vazquez M, Rodríguez G, Samper P, Fleta J (2005) Electrocardiographic and echocardiographic findings in malnourished children. J Am Coll Nutr. 24(1):38-43

22. Singh GR, Malathi KE, Kasliwal RR, Ommar ASHOK, Padmavati S, Ramji S (1989) An evaluation of cardiac function in malnourished children by noninvasive methods. Indian Pediatr. 26(9):875-881

23. Phornphatkul C, Pongprot Y, Suskind R, George V, Fuchs G (1994) Cardiac function in malnourished children. Clin Pediatr (Philadelphia). 33:147-154 
24. Abu FNH, El Sayh Kl, Shams H, Badrawy H (2010) Myocardial dysfunction in malnourished children. Ann Pediatr Cardiol. 3(2):113

25. El-Sayed HL, Nassar MF, Habib NM, Elmasry OA, Gomaa SM (2006) Structural and functional affection of the heart in protein energy malnutrition patients on admission and after nutritional recovery. Eur J Clin Nutr. 60(4):502-510

26. Kerac M, Bunn J, Chagaluka G et al (2014) Follow-up of post-discharge growth and mortality after treatment for severe acute malnutrition (FuSAM Study): a prospective cohort study. PLoS One. 9(6):e96030

27. Public Health Foundation of India (PHFI). Perception of caregivers about the management of severe acute malnutrition children at Malnutrition Treatment Center (MTC) and prospects of children after rehabilitation in Jharkhand 2012. http://pdf.usaid.gov/pdf_docs/PA00JD7G.pdf.

28. Stettler N, lotova V (2010) Early growth patterns and long-term obesity risk Curr Opin Clin Nutr Metab Care. 13:294-299

29. Dulloo AG (2008) Thrifty energy metabolism in catch-up growth trajectories to insulin and leptin resistance. Best Pract Res Clin Endocrinol Metab. 22:155-171

\section{Publisher's Note}

Springer Nature remains neutral with regard to jurisdictional claims in published maps and institutional affiliations.

\section{Submit your manuscript to a SpringerOpen ${ }^{\circ}$ journal and benefit from:}

- Convenient online submission

- Rigorous peer review

- Open access: articles freely available online

High visibility within the field

- Retaining the copyright to your article

Submit your next manuscript at $\boldsymbol{\wedge}$ springeropen.com 